\title{
CÂmaras Municipais e OrdenançAS no Estado do Maranhão e Grão-PARÁ: CONSTItUIÇÃo de UMA ELITE DE PODER NA AMAZÔNIA SEISCENTISTA ${ }^{1}$
}

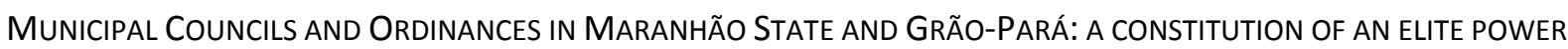
IN THE $17^{\text {TH }}$ CENTURY AMAZON

\author{
Rafael Ale Rocha* \\ rafael_ale_rocha@yahoo.com.br
}

RESUMO: Com esse artigo, pretendemos abordar a formação das elites locais de Belém e São Luís. Observaremos que por um lado, a monarquia procurava garantir o monopólio das principais instituições de poder local, as Câmaras Municipais e as tropas de ordenanças, às elites residentes. Por outro, esses espaços eram procurados por esses grupos que, alegando serviços imprescindíveis à existência da colônia, solicitavam privilégios que os equiparassem às superiores linhagens fidalgas signos de distinção específicos, como os privilégios da Câmara da cidade do Porto, e a transmissão hereditária do oficialato de instituições de comando e governo.

PALAVRAS-ChAVE: Amazônia Colonial, Elites Locais, Instituições Locais de Poder.

ABSTRACT: With this article, we aim at addressing the development of the local elites of Belém and São Luís. We will see that, on the one hand, the monarchy sought to ensure the monopoly of major local government institutions, the City Council and the ordinance troops, to the local elites, and on the other, these spaces were sought by these groups claiming essential services to the existence of the colony, while requesting privileges that the higher noble lineage had - specific signs of distinction, such as the privileges of the City Council of Porto and the inheritance of the officership of command and government institutions.

KEYWORDS: Colonial Amazon, Local Elites, Local Institutions of Power.

\section{Introdução}

Em estudo sobre a tropa paga do Estado do Maranhão e Grão-Pará, centrado na segunda metade do século XVII (1644-1684), ilustrou-se uma tendência determinada: em primeiro lugar, a regularização ou normatização do oficialato militar (capitão mor, sargento mor e capitão) e o controle do provimento dos postos oficiais pelo centro monárquico (por meio de um processo de seleção específico, gerenciado pelo Conselho Ultramarino, e da obrigatoriedade da patente régia); em segundo lugar, a consequência desse primeiro aspecto, qual seja a concessão preferencial desses cargos aos "não locais", isto é, àqueles que não pertenciam às famílias locais, não estabeleciam carreiras duradouras na região antes de galgar os postos em questão e/ou, mesmo, nunca serviram no Estado. Esses estudos demonstram que a carreira militar de boa parte desses oficiais, usualmente bastante extensa (normalmente mais de dez anos), era caracterizada pela circulação desses

\footnotetext{
${ }^{1}$ A pesquisa para a elaboração desse artigo só foi possível através do auxílio da Universidade do Estado do Amazonas (UEA) por meio do programa de produtividade acadêmica.

* Professor da Universidade do Estado do Amazonas. Doutor em História Social pela Universidade Federal Fluminense.
} 
homens em variadas partes do império. Na verdade, algumas dessas características aqui delineadas (a carreira extensa e a considerável presença dos "de fora"), por vezes, eram as justificativas para as escolhas dos oficiais realizadas pelo centro monárquico (conforme as consultas do Conselho Ultramarino e as resoluções régias) (ROCHA, 2013, cap. I e II).

No presente artigo, pretendemos demonstrar que os oficiais da Câmara e da tropa de ordenança, os chamados "homens bons", estavam relacionados a uma lógica diferenciada: integravam a chamada elite "local". Dentre outras questões, pelo menos três elementos inter-relacionados explicam a construção dessa elite: a representação de sociedade vigente no Antigo Regime português; a legislação régia, que cedia o monopólio dos principais cargos locais de comando e/ou governo - principalmente os ofícios das câmaras municipais e das ordenanças - aos membros das chamadas "principais" famílias locais ou "nobreza da terra"; e, por fim, a atuação dessas famílias na conquista, defesa e/ou na colonização da região.

\section{As Nobrezas em Portugal na Era Moderna}

Quanto ao conceito de nobreza, sabe-se que a sociedade era representada pela imagem dos três estados ou ordens, que, grosso modo, ilustrava a naturalidade da hierarquia social (ou seja, esta independia de uma vontade) e relacionava essa hierarquia às funções sociais de cada estado ou ordem e aos seus respectivos privilégios (ou à ausência dos mesmos) - nobreza/guerra, clero/sacerdócio e povo/trabalho. Entre os séculos XVI e $\mathrm{XIX}$, tendo em mente a multiplicação das funções sociais e dos privilégios, o conceito de nobreza sofreu mutações diversas. De forma bastante generalizada, a literatura (tratadistas, juristas, canonistas, entre outros) tendeu a diferenciar diversos graus de nobreza: a chamada nobreza "natural" - hereditária ou generativa, mas confirmada pela monarquia; a nobreza "política" ou "civil" - estabelecida pela tradição, pela ocupação de determinados cargos e por mercês régias específicas; o "estado do meio" - os intermediários entre os "vis", aqueles que executavam trabalhos manuais e por isso estavam relacionados ao estado ou ordem do povo, e os "limpos"; a "primeira nobreza da corte" - distintos, portanto, da nobreza provinciana pelo local de residência; e os "grandes" - a aristocracia superior que, também estabelecida na corte, era identificada pelos títulos de nobreza mais distintos (duques, marqueses e condes). O resultado, característica particular da sociedade portuguesa, fora a diferenciação entre os termos nobreza - os não "vis" - e fidalguia - associada à nobreza 
natural. Estudos sobre a nobreza portuguesa demostram que esses graus de nobreza estavam relacionados às diversas instituições da monarquia e/ou às mercês régias (signos de distinção que normalmente conferiam renda ou pensão aos seus detentores). Nesse sentido: a nobreza natural era composta por aqueles que possuíam os nomes inscritos nos livros de matrículas da Casa Real (foros de fidalguia específicos), integravam o braço da nobreza nas assembleias de cortes, possuíam senhorios (donatários de territórios) e detinham títulos de nobreza (barões, viscondes, condes, marqueses e duques); a nobreza civil comportava os oficiais das câmaras dos principais municípios, os oficiais das tropas pagas (os capitães e os postos superiores a este), os cavaleiros de ordem militar (ordens de Cristo, Santiago e Avis) e aqueles que atuavam em diversos outros cargos (XAVIER; HESPANHA, 1998; MONTEIRO, 2003, cap. 1).

Cabe informar que, a partir do século XVI, as "provas de nobreza" que legitimavam a "qualidade" de um indivíduo - uma condição, conforme tais provas, adquirida antes de nascer - se tornaram cada vez mais comuns na península Ibérica. Se algumas provas, como o "viver à lei da nobreza" (com criados e cavalos), eram mais simples de ultrapassar, outras, a exemplo da "pureza de sangue" (não pertencer a ou descender de raças infectas, ou seja, aquelas que professavam qualquer religião não cristã), eram de difícil superação (MONTEIRO, 2005, p. 6-8). Outra prova importante era a ausência do defeito mecânico (o trabalho manual) nos postulantes à nobreza e/ou nos seus ascendentes, que, como se sabe, era um elemento importante para adquirir mercês como um hábito de cavaleiro de ordem militar.

É notório que, entre os séculos XVII e XIX, a fidalguia, cada vez mais concentrada na Corte, passou a ocupar prioritariamente os principais cargos da monarquia - a presidência dos conselhos ou tribunais, a chefia das missões diplomáticas importantes, os mais altos cargos da igreja, os comandos dos exércitos do reino, os governos das principais praças do ultramar, entre outros - e, com isso, a concentrar em suas mãos as mais distintas e/ou rendosas mercês - os títulos de nobreza, os senhorios e as comendas. ${ }^{2}$ Além da antiguíssima ideia de que nas principais "casas" (famílias nobres) eram encontrados os mais capazes

\footnotetext{
${ }^{2}$ As comendas representavam bens (normalmente terras) que geravam rendas a serem administradas por servidores do monarca. Conforme Nuno Monteiro, no século XVIII as rendas provenientes dessas mercês correspondiam a quase metade do rendimento das casas dos grandes - o que demonstra a importância do serviço e dessa doação régia para as casas aristocráticas. (MONTEIRO, 2003a, p. 260-263).
} 
servidores, isso foi possível a partir das ações da monarquia - restringindo a concessão de títulos de nobreza e instrumentalizando a Lei Mental ${ }^{3}$ - e dos grupos sociais - por meio da adoção de um ethos específico, qual seja, servir visando a obtenção de novas mercês para a casa, estabelecer bons casamentos (endogamia matrimonial) ou o celibato a determinados membros da família e concentrar os patrimônios da casa nas mãos do seu primogênito. Em síntese, essa aristocracia era pouco numerosa e bem delimitada, enquanto que a nobreza civil ou política era difusa e crescera cada vez mais em número de membros (MONTEIRO, 2003a).

À outra categoria de nobreza pertenciam as oligarquias espalhadas pelos diversos municípios. Estas, diferente da aristocracia de corte, estavam relacionadas às instituições de poder local: as câmaras e as tropas de ordenança. Para a generalidade das câmaras e das ordenanças, os autores portugueses parecem não enquadrar automaticamente os seus oficiais em qualquer das categorias de nobreza acima mencionadas. Na verdade, no que se refere às câmaras, só as tradicionalmente reservadas aos nobres conferiam nobreza por ofício (juízes, vereadores, procuradores e almotacés). ${ }^{4}$ Além do mais, os procuradores das diversas Câmaras Municipais não integravam o braço da nobreza nas assembleias de cortes. O braço da nobreza, representado pelos títulos de nobreza, pelos senhorios, pelos alcaidesmores e por pessoas com permissões especiais, era convocado por carta régia. Por seu turno, os "homens bons" da Câmara, que desde o século XVI se intitulavam "nobreza da terra", elegiam os seus procuradores para o braço do povo. (MONTEIRO, 1998a, p. 298). Em outro estudo, destacando o monopólio dos cargos das câmaras e das ordenanças por parte dessa nobreza local e a sua presença no braço do povo durante as assembleias de cortes, Nuno Monteiro destaca que "identificada em certos registros corográficos, a nobreza das terras era-o também, como se disse, no vocabulário oficial" (MONTEIRO, 1996, p. 61 e 62).

\footnotetext{
${ }^{3}$ A Lei Mental, instituída em fins da Idade Média, regularizava a sucessão das doações régias (títulos, senhorios, comendas, etc.) pelos princípios de varonia e primogenitura. Essas doações eram usualmente concedidas em uma vida. Por isso, normalmente dependiam de novos serviços para a efetiva transmissão hereditária.

${ }^{4}$ Antônio Hespanha, baseado em um jurista seiscentista, apresenta opiniões divergentes sobre as ordenanças: ora afirma que pertenciam à nobreza política, ora afirma que não (XAVIER; HESPANHA, 1998, p. 136 e 137; HESPANHA, 1994, p. 310). Em obra de início do século XIX, Luiz da Silva de Pereira de Oliveira afirma que competiam aos postos das ordenanças privilégios diversos e destaca que os cargos de capitão mor, sargento mor e capitão deveriam ser providos por pessoas de "melhor nobreza". Contudo, o autor informa que "tudo isto ainda não tem podido brotar aquelle gráo de estimação que se deve a estes Póstos, e não sei porque fatalidade muitos Nobres se desvião de servillos" (OLIVEIRA, 2002, p. 46) Quanto aos oficiais das câmaras, só enobreciam nas terras nas quais era costume servirem nobres. (XAVIER; HESPANHA, 1998, p. 136 e 137).
} 


\section{Câmaras e Ordenanças no Reino e no Estado do Brasil}

No que se refere às câmaras e às ordenanças, a legislação régia garantia o oficialato dessas instituições às "principais" ou "mais nobres" famílias locais. Nesse sentido, conforme a legislação: os postos oficiais das ordenanças deveriam ser ocupados pelos "principais das terras" (regimento das ordenanças de 1570); os capitães-mores dessas tropas seriam os "senhores dos lugares" (regimento das ordenanças de 1570) ou as "pessoas da melhor nobreza, cristandade e desinteresse" (alvará de 1709); os eleitores dos oficiais camarários (juiz ordinário, vereador e procurador) deveriam ser os "melhores dos lugares" (Ordenações Filipinas de 1603); os eleitores desses cargos seriam os "mais nobres e da governança da terra" e os eleitos deveriam ser "sem raça alguma" (alvará de 1611); os almotacés seriam "gente nobre e dos melhores da terra na forma da Ordenação", não poderiam ser eleitos para os demais postos pessoas "que eles ou seus pais fossem, ou houvessem sido oficiais mecânicos" e, caso isso ocorresse, as eleições estariam anuladas (alvará de 1618); e, por fim, a governança não poderia ser cedida a "mecânicos, nem peão algum [...] se não nobres das partes, e qualidades para isso, e filhos de nobre" conforme "a forma de minhas Ordenações e leis" (alvará de 1651). Em relação às câmaras, uma série de leis impôs a tutela dos magistrados - ouvidores ou corregedores - nas eleições.

O alvará de 1670 consagrava essas tendências e instituía maior controle sobre a escolha dos eleitores e dos elegíveis, pois os ouvidores ou corregedores escolheriam os informantes (dois ou três) que elaborariam a lista dos elegíveis (posteriormente escolhidos pelos eleitores). Em seguida, a lista dos elegíveis e a relação dos votos eram enviadas ao desembargo do Paço (tribunal central) ou aos senhores das terras para a confirmação. Quanto às ordenanças, por sua vez, as câmaras escolhiam os oficiais desse modelo de tropa desde o regimento de $D$. Sebastião de 1570. Em síntese, eleitores e eleitos pertenciam a um círculo fechado e distinto que tendia à hereditariedade. A legislação explicava essa tendência a partir da ideia de que os membros das famílias mais antigas e prestigiadas possuíam uma "autoridade natural" e, por serem os mais nobres e ricos, governariam com "desinteresse", isto é, sem confundir os interesses pessoais com os da coletividade (BICALHO, 2001, p. 212 e 2013; OLIVEIRA, 2002, p. 60-64; MONTEIRO, 1998b, p. 288 e 289; MONTEIRO, 2003b, p. 4348; MONTEIRO, 1996, p. 60-63 e 162 e 163). 
Contudo, como destaca Nuno Monteiro, durante o século XVIII a nobreza da terra cada vez menos se confundia com os senhores das regiões (aqueles que gozavam dos senhorios das terras), pois, após a aclamação da nova dinastia e a Guerra da Restauração de Portugal (1640-1668), esses passaram a se fixar na corte em busca de mercês e honras da monarquia, tornaram-se distintos e distantes (por "divórcio social") da nobreza das províncias e enfraqueceram as suas respectivas relações clientelares nessas mesmas localidades (MONTEIRO, 1996, p. 61 e 62; MONTEIRO, 1998a, p. 332).

Na verdade, conforme os estudos do autor sobre o assunto, as elites que atuavam nas diversas câmaras do reino possuíam determinadas características: uniformidade institucional (as mesmas regras para as eleições eram contempladas em todas as câmaras) e desigualdade entre as categorias sociais dos elegíveis dos diversos conselhos. Assim sendo, analisando a riqueza e a condição social dos elegíveis, segundo fontes da virada do século XVIII para o século XIX, Monteiro pôde concluir: as casas ou famílias com as maiores rendas e distinções estavam concentradas na corte e não nas diversas câmaras do reino, pois eram raros os senhores/donatários de terras e os comendadores no rol dos elegíveis; a nobreza titulada e os grandes não eram eleitos para os concelhos; as câmaras mais ricas eram as mais distintas; e, dentre outras questões, havia enorme diversidade social entre os elegíveis para as diversas câmaras, isto é, alguns conselhos estavam reservados a comendadores e/ou fidalgos da Casa Real, dos quais eram excluídos inclusive cavaleiros de ordem militar, enquanto outras eram ocupadas por "mecânicos" e lavradores (havia, mesmo, certa permissividade para tal). O resultado dessa configuração fora o fato de que, se em algumas regiões uma fidalguia de linhagem medieval procurava manter afastada das câmaras uma recente nobreza civil ou política, para a maior parte dos municípios mais ricos e destacados os elegíveis correspondiam à convergência dessa fidalguia antiga com grupos ascendentes. Assim, por um lado, as elites locais não desejavam participar das câmaras menores e muitas das mais antigas e ricas casas fidalgas das províncias evitavam atuar até nos concelhos importantes, pois buscavam um estatuto nobiliárquico superior possibilitado pelo serviço à monarquia. Por outro lado, a atuação nas câmaras era almejada pelas elites em vias de ascensão (MONTEIRO, 2003, p. 51-74; MONTEIRO, 1998b, p. 288-291; MONTEIRO, 1996, p. 163-165).

Já as ordenanças, para o mesmo autor, era "a principal via institucional local para a 
mobilidade social", ou seja, havia "uma distinção importante no que se refere à relação entre os oficiais das ordenanças e os elegíveis para as câmaras". Isso porque os postos desse tipo de tropa eram vitalícios e nos municípios mais distintos e fidalgos somente o oficialato superior da ordenança poderia galgar cargos nas Câmaras - capitães mores e sargentos mores, que, normalmente, eram fidalgos da Casa Real e/ou cavaleiros de ordem militar. Mas, por outro lado, nas Câmaras menos distintas atuavam capitães e alferes de ordenança (MONTEIRO, 2003, p. 72).

Em síntese, a maior parte dessa oligarquia cristalizou-se na segunda metade do século XVII e não pertencia à antiga fidalguia, mas comportava integrantes do estado do povo que, pela conduta, modo de vida e exercício do governo concelhio, estabeleceu-se nas “bordas da nobreza” (MONTEIRO, 1998b, p. 288; MONTEIRO, 1996, p. 162).

Da mesma forma, a historiografia sobre as elites do Brasil colonial apresenta, em relação às mais diversas regiões, uma oligarquia bem delimitada e com tendências hereditárias. Apesar de destacar a participação de mestiços em determinadas Câmaras do império, Charles Boxer já considerava que no ultramar, como em Portugal, "os vereadores tinham se tornado mais uma oligarquia que se perpetuava no poder, distribuindo os cargos entre eles próprios e seus parentes" (BOXER, 1994, p. 298).

Na Bahia dos séculos XVII e XVIII, conforme os estudos de Stuart B. Schwartz, Rae Flory e David G. Smith, a Câmara de Salvador e o oficialato da ordenança eram espaços de atuação privilegiados dos senhores de engenho. Os autores destacam a heterogeneidade do grupo. Isso porque, principalmente no século XVIII, era aberto à entrada de comerciantes, em sua maioria reinóis, que se uniam à elite tradicional por casamentos, investiam em terras e na produção açucareira e passavam a ocupar cargos na câmara de Salvador e na ordenança da Bahia (SCHWARTZ, 2005, p. 227, 228, 232 e 233; FLORY: SMITH, 1978, p. 574, 575, 579583, 590-591). Mas Schwartz destaca uma diferenciação, reconhecida pelos contemporâneos em fins do século XVIII, entre uma fechada e "tradicional aristocracia do açúcar" e os demais senhores de engenho (SCHWARTZ, 2005, p. 228).

No Rio de Janeiro, durante o mesmo período, uma elite formada por senhores de engenho procurou monopolizar os ofícios camarários. Como mostram os estudos de João Luís Fragoso, a maioria das famílias senhorias do século XVII (aquelas que possuíam um ou mais engenhos) foi originada por um oficial da coroa que empreendeu a conquista da região. 
Em seguida, esses homens passaram a realizar casamentos endogâmicos e a ocupar majoritariamente os postos oficiais da Câmara. Esse domínio teria perdurado até meados do século XVIII (FRAGOSO, 2001, p. 42, 47 e 52-55; FRAGOSO, 2005, p. 56-68). Para tanto, conforme os estudos de João Luís Fragoso e Maria Fernanda Bicalho, a elite senhorial, diante da monarquia, valia-se de estratégias específicas: o uso do termo "principal" ou "nobre" para se auto identificar; o papel de conquistador; a condição de natural da região; o governo exercido pelos antepassados; a legislação régia que, como observamos, garantia aos mais "nobres" ou "principais" e suas famílias os cargos camarários e barrava os estigmatizados (os camarários do Rio de Janeiro citavam, por exemplo, as Ordenações de 1603 e a lei de 1611); e, por fim, os estigmas de qualidade - "defeito mecânico" e "sangue impuro" -atribuídos aos comerciantes usualmente identificados como reinóis, que, com o auxílio dos governadores e ouvidores, por vezes conseguiam galgar postos na câmara. Esses comerciantes, por sua vez, arrogavam-se na condição de melhor servir à monarquia com seus cabedais e, em função dessa condição econômica, atuar com "desinteresse". (FRAGOSO, 2005, p. 35-46; BICALHO, 2001, p. 212-218; BICALHO, 2003, p. 373-391). Observamos que, ao lado da "autoridade natural", o desinteresse era um dos princípios por meio dos quais a legislação procurava garantir os postos das Câmaras e das ordenanças aos poderosos locais.

Antes de Fragoso e Bicalho, os pioneiros estudos de Evaldo Cabral de Mello demonstram que, durante a segunda metade do século XVII, estratégia muito parecida apresentava a elite dos senhores de engenho de Pernambuco - o uso do termo "nobre" para se autoidentificar a conquista, a naturalidade, a legislação já promulgada e os estigmas de qualidade atribuídos aos comerciantes usualmente identificados como reinóis. A ideia da conquista, contudo, foi substituída pela da restauração - referente às guerras, ocorridas entre 1630 e 1654, contra os holandeses que ocuparam o litoral das capitanias do norte da América Portuguesa. À semelhança dos senhores de engenho do Rio de Janeiro, constituíam um grupo fechado, por casamentos endogâmicos, e visavam os mesmos objetivos: o monopólio dos principais cargos da câmara de Olinda, mas também da ordenança de Pernambuco, diante dos governadores e ouvidores, que, por vezes, facilitavam o acesso a esses postos aos comerciantes reinóis que habitavam o Recife. Esses últimos eram denegridos pela açucarocracia por meio do estigma de mecânicos (MELLO, 2008, p. 157-172; MELLO, 2003, p. 142, 143, 147, 148, 186-89 e 192-210). Dentre os principais argumentos que 
os senhores de engenhos apresentavam nesses conflitos constavam a naturalidade local e os méritos, que arrogavam para si, da expulsão dos holandeses da região. Através do topos "à custa de nosso sangue, vidas e fazendas" afirmavam que, em nome da lealdade à nova dinastia (aclamada em 1640), expulsaram, sem o dispêndio da real fazenda, os flamengos de Pernambuco (MELLO, 2003; MELLO, 2008, cap. 3).

\section{Câmaras e Ordenanças no Estado do Maranhão e Grão-Pará}

No que se refere às câmaras do Estado do Maranhão e Grão-Pará (São Luís, capital da capitania do Maranhão, e Belém, capital da capitania do Pará), inexistem estudos que descrevam detalhadamente os seus ocupantes. Mas é conhecido que, em relação às Câmaras de São Luís e Belém, os "homens bons" solicitaram da monarquia privilégios especificamente os concedidos, em 1490, à cidade do Porto - em função da atuação na guerra, ocorrida entre 1641 e 1644, de expulsão dos holandeses do Maranhão. O argumento das duas Câmaras, referente aos privilégios solicitados na década de 1650 e concedidos pelo monarca no mesmo período, era o dispêndio de vidas e fazendas, por parte das "principais" famílias, nesse conflito. Como veremos, com a aquisição desses privilégios, visavam afastar dos cargos das câmaras de São Luís e Belém aqueles que não integravam um grupo prédeterminado: as famílias que investiram seus sangues e suas fazendas na conquista, restauração e/ou defesa do Estado.

É importante informar que, conforme Nuno Monteiro, a câmara da cidade do Porto, no século XVIII, comportava os mais distintos - somente fidalgos da Casa Real - e ricos homens bons. (MONTEIRO, 2003, p. 54-60). Além do mais, como veremos, os privilégios dos cidadãos do Porto ${ }^{5}$, concedidos à Câmara desta cidade por carta régia de 1490 , eram os mesmos que foram conferidos aos fidalgos, infanções e ricos homens do reino. Essas duas últimas categorias, segundo Luiz da Silva Oliveira, eram as mais graduadas da Idade Média portuguesa (somente após as suas respectivas extinções é que foram criados os títulos de barão, visconde, conde, marquês e duque) e deram origem aos foros de fidalguia (fidalgos da Casa Real) mais distintos (OLIVEIRA, 2002, p. 212-214). Por outro lado, a concessão desses mesmos privilégios às câmaras ultramarinas, como destacou Maria Fernanda Bicalho, estava

\footnotetext{
${ }^{5}$ Em Portugal, "nobres" locais ou "cidadãos" representavam aquele grupo estabelecido nas câmaras que alardeava pureza de sangue, prestígio, reconhecimento público e precedências. Ou seja, pelo modo de vida, conseguia permanecer nas "bordas da nobreza". Os cidadãos eram responsáveis pela res publica, isto é, a coisa pública. Por isso, estavam intimamente relacionados à governança ou às câmaras municipais (BICALHO, 2001, p. 204-205).
} 
intimamente relacionada à aclamação da nova dinastia e/ou às guerras contra os holandeses no Atlântico Sul, pois, por pelo menos um desses motivos, adquiriram os mesmos privilégios as câmaras do Rio de Janeiro (1642), Salvador (1646) e São Paulo de Luanda (1662) (BICALHO, 2001, p. 205-206). Ou seja, tratava-se de um seleto grupo no qual os camarários de Belém e São Luís passavam a integrar.

No que se refere aos privilégios da cidade do Porto, como mostra o estudo de Helidacy Corrêa, tratava-se de uma antiga solicitação dos camarários de São Luís, referente, nesse caso, à expulsão dos franceses do Maranhão ocorrida no ano de 1615 (CORRÊA, 2011, p. 41-43). Em abril de 1655, o Conselho Ultramarino analisava uma solicitação do procurador do Maranhão, que, estando na Corte, requisitava maior agilidade no despacho de papéis. O procurador demandava a provisão régia que concedia os privilégios dos "cidadãos do Porto" à Câmara de São Luís, prometido pelos reis anteriores e já concedido pelo monarca vigente, valendo-se de um argumento específico: a "restauração" do Maranhão. O conselho ultramarino alertava que, em resposta a uma solicitação do comandante da restauração, o monarca já havia concedido essa mercê, ainda no ano de 1645, como remuneração pela expulsão dos holandeses do Maranhão. Mas os despachos não prosseguiram. O conselho, embora "se não haver tirado despacho pelo dele [do requerimento] no tempo ordinário", aconselhava o lançamento da provisão régia (AHU Maranhão, cx. 3, doc. 361) ${ }^{1}$. A provisão que concedia os privilégios dos cidadãos do Porto aos oficiais da Câmara de São Luís, destacando essa mercê como remuneração da restauração e a necessidade de manter os vassalos "animados" para continuar servindo por meio de tal benesse, foi promulgada seis dias depois (15/04/1655) (ANTT, Chancelaria de D. João IV, livro. 27, f. 118v.)². Em junho do mesmo ano, o procurador do Pará, o capitão Manuel Guedes Aranha, interviu junto ao monarca para solicitar a concessão dos mesmos privilégios à Câmara de Belém. Para tanto, alegava a atuação dos paraenses no mesmo conflito - a restauração do Maranhão. Guedes Aranha, que tal como o procurador do Maranhão também já estava no reino, apresentava a provisão da mercê concedida aos "moradores" do Maranhão (os privilégios dos cidadãos do Porto) e afirmava que os paraenses eram ainda mais beneméritos da mesma benesse, pois, se os maranhenses defenderam os seus bens durante os embates contra os holandeses, os moradores do Pará "largaram suas casas, famílias, e fazendas por irem ajudar a recuperar a dita cidade [São Luís]". (AHU Pará, cx. 2, doc. 95)³. Apresentados como "cidadãos" de Belém 
pela descrição do Conselho Ultramarino, a petição do procurador, destacando a necessidade de remunerar a restauração e manter esses vassalos "animados" para continuar servindo, resgatava aquele velho topos:

[a restauração foi levada a cabo] "[...] não sem custo de algumas mortes de seus pais, filhos, irmãos, e companheiros, e dispêndio de suas fazendas, e mantimentos, com que muitos meses socorrerão o Maranhão até se refazer de mês [sic.], no que não concorreu ajuda alguma deste reino, nem dispêndio da fazenda de V. Majestade" (AHU Pará, cx. 2, doc. 95).

O Conselho Ultramarino, pelos motivos levantados pelo procurador, julgou coerente a concessão da mercê. A provisão que cedia os referidos privilégios aos oficiais da câmara de Belém, cujo texto era muito semelhante à concedida aos oficiais da câmara de São Luís, foi promulgada no mês seguinte (20/07/1655) (ANTT, Chancelaria de D. João IV, livro. 27, f. 118v.). Os privilégios referidos em ambas as provisões são aqueles abordados em uma carta régia de 1490, que, outorgados para remunerar serviços importantes e para garantir que os beneficiados mantivessem a condição de bons servidores, garantia aos cidadãos do Porto alguns privilégios próprios de fidalgos, de infanções, de ricos homens e da câmara de Lisboa. É o que informava um requerimento dos "cidadãos" (já é assim que se autonomeiam) de São Luís e Belém, que anexava a referida carta régia de 1490 e uma das provisões acima mencionadas, remetido ao monarca para salvaguardar os privilégios conquistados por ambas as Câmaras. Por este, elaborado no ano de 1655, os cidadãos solicitavam a obediência aos privilégios adquiridos diante dos supostos abusos cometidos por alguns ministros. Quais sejam: castigar os suplicantes, seus filhos e seus netos em desobediência às leis régias e ao "grau de nobreza" (outro termo utilizado para se autonomear) desses homens, isto é, "metendo-os em prisão injuriosa, denegando-lhes suas menagens"; e recrutar, forçadamente, e, "com violência", os filhos e os netos dos cidadãos. É que dentre os principais privilégios concedidos pela carta régia de 1490 , anexada no requerimento dos cidadãos, constavam: só poderiam ser "metido a tormentos", em função de crimes cometidos, como o eram os fidalgos; à semelhança dos mesmos fidalgos, não seriam presos sem as devidas "menagens"; e, por fim, indivíduos específicos que integravam as suas respectivas redes de dependentes, nomeadamente os que "continuamente com eles viverem", não poderiam ser constrangidos a atuações em guerras, mas, tão somente, o fariam sob o comando dos "cidadãos" (AHU Maranhão, cx. 3, doc. 367) ${ }^{4}$. Observe que, no requerimento referido, já utilizavam os termos cidadãos ou nobres para se autonomear. Para 
reforçar seus argumentos, recorriam, mais uma vez, ao topos mencionado:

[citavam a importância de observar os referidos privilégios, enquanto remuneração da restauração do Maranhão], "mandando cumprir-lhe [...] visto os não terem desmerecido, nem esperarem desmerecer nunca a $\mathrm{V}$. Majestade esta grande honra, que custou a ganhar a seus pais, avós a custa de suas próprias fazendas, sangue e vidas, para deixarem aos suplicantes, seus filhos, e netos [...] pois é certo que as honras e prêmios dos monarcas soberanos, para seus leais vassalos são os maiores incentivos, que faz obrar ações heroicas em aumento, e defensa da sua Real Coroa (AHU Maranhão, cx. 3, doc. 367).

Aqui surgia a preocupação de delimitar claramente quem eram esses cidadãos, nobres e/ou privilegiados: os restauradores e seus descendentes, isto é, linhagens específicas, que procuravam barrar ações arbitrárias e/ou proteger os privilégios adquiridos frente aos governadores ou ministros régios. Exemplo disso consta numa carta da Câmara de São Luís, enviada ao monarca em 1662, segundo a qual os governadores antecessores de Rui Vaz de Siqueira (1662-1667) costumavam intervir nas "jurisdições" da mesma Câmara e "mal tratavam" ou "molestavam" os vereadores que os impediam (desterrando, inclusive, alguns desses camarários). Por esse motivo, determinados "homens nobres" se recusavam a atuar nesse conselho ou, uma vez nessa instituição, não o faziam de forma satisfatória por medo das arbitrariedades dos governadores. Assim sendo, a Câmara solicitava do monarca, o que foi atendido pelo mesmo (conforme resolução à margem do documento), a proibição das intervenções dos governadores no governo da câmara e o respeito aos privilégios concedidos pelo rei aos camarários. Ao que parece, referiam-se à remuneração da restauração do Maranhão, pois lembravam que a "real condição de V. Majestade é ter memória para dar remuneração a cada um conforme seus serviços" (AHU Maranhão, cx. 4, doc. 453) ${ }^{5}$. Em 1698, era a vez da Câmara de Belém se queixar com o monarca (afirmando que os ministros seculares e eclesiásticos "vos não guardarem os privilégios que vos são concedidos"), que, em carta régia, requisitava da própria câmara detalhamentos sobre o assunto (AHU cód. 268, f. 137$)^{6}$.

Em síntese, no decorrer do século XVII, os nobres, cidadãos ou privilegiados representavam um mesmo grupo, que possuíam nas instituições locais de poder - Câmaras e, como veremos a seguir, ordenanças - e nas ideias de conquista, restauração e/ou colonização os seus vetores de identificação. Além do mais, como vimos, esse grupo constituía verdadeiras linhagens, posto que o status era transmitido hereditariamente à 
semelhança dos fidalgos. Cabia a esse grupo, portanto, monopolizar os principais cargos locais de administração e comando. Em relação à Câmara de São Luís, Helidacy Corrêa demonstra que os primeiros camarários foram eleitos, em 1615, por Alexandre de Moura, capitão mor que comandara uma armada para conquistar a região, logo após a expulsão dos franceses. Têm-se notícia, por correspondência de 1619, de que os primeiros camarários eram imigrantes açorianos. Conforme Corrêa, a partir desse período, quando acionavam a monarquia para solicitar privilégios e/ou solucionar conflitos, os oficiais da Câmara se apresentavam como "conquistadores", "homens bons da conquista" e/ou "herdeiros dos primeiros conquistadores" e descreviam as ações que realizaram e continuavam a realizar, com os seus esforços pessoais e seus cabedais, na defesa do território e na organização política e administrativa do mesmo (CORRÊA, 2011, p. 27-42). Em alguns momentos, ao que parece, referiam-se diretamente à conquista, contra os franceses (1615), e à restauração, contra os holandeses (1641-1644). Foi o caso, ocorrido em 1676, da rejeição à eleição de um juiz ordinário. Para tornar ilegal a eleição, o termo de vereação respectivo relembrava os dois conflitos mencionados, informava que o referido eleito não integrava a parentela ou a linhagem dos conquistadores e, por fim, solicitava o monopólio dos cargos da câmara a essas mesmas famílias (CORRÊA, 2011, p. 43-46).

Quanto à câmara de Belém, uma carta régia de 1698 informava que alguns soldados pagos, mecânicos (aqueles que trabalhavam com as mãos) e degredados galgavam postos na câmara para escapar do serviço militar. Proibindo essa prática, então, o monarca ordenava ao governador Antônio de Albuquerque Coelho de Carvalho (1690-1701) a obediência às Ordenações Filipinas (1603), que, segundo a carta régia, garantia esses cargos exclusivamente "aos filhos de homens nobres, e cidadãos, e que de nenhuma maneira sejam admitidos, na governança, aqueles com quem não concorrer esta circunstância" (AHU, cód. 268 , f. $138 v$.) $)^{7}$. Essa carta régia, inclusive, ordenava a criação da companhia de ordenança dos privilegiados para nela alistar os "filhos dos nobres", pois esses se recusavam a atuar como soldados nas companhias comuns, o que, como pontuamos, era um dos privilégios concedidos pelo monarca aos camarários em 1655. Observe que, a essa altura, o termo nobreza, como demarcador do estatuto privilegiado de determinado setor da elite local, já era incorporado oficialmente pela monarquia.

Em fins do século XVII, listas de cidadãos ou nobres e de seus filhos, assim como 
listas de oficiais e praças das ordenanças, dos integrantes da companhia da nobreza (cidadãos ou nobres) e dos alistados na companhia dos privilegiados (filhos desses cidadãos ou nobres), foram elaboradas pela câmara de S. Luís e, talvez, pela câmara de Belém. As listas delimitavam claramente os indivíduos integrantes dessas linhagens e, já no século XVIII (décadas de 20 e 30), foram enviadas ao conhecimento da monarquia (APEM, Livro da Companhia da Nobreza, 1689-1710; AHU Pará, cx. 11, doc. 9749; AHU Pará, cx. 12, doc. 1141 $1^{10}$; e AHU Pará, cx. 12, doc. $1142^{11}$ ).

Em relação à ordenança, o regimento concedido em 1655 ao governador André Vidal de Negreiros (1655-1656), embora permitisse ao governador a regulação do "governo" do Estado por meio da organização dos mais diversos cargos, ordenava a expressa obediência ao regimento de D. Sebastião de 1570 , que, como pontuamos, entregava à câmara a eleição dos principais postos desse modelo de tropa (MENDONÇA, 1972, p. 702 e 704). Sobre esse último regimento, já observamos, os cargos deveriam ser destinados aos "principais". O regimento remetido a Negreiros também permitia ao governador a criação de postos de ordenança em tempos de guerras (posteriormente seriam reformados), mas o proibia em tempos de paz (MENDONÇA, 1972, p. 708). Essa normatização, ao que parece, vigorou nos séculos XVII e XVIII, pois, em 1772, o governador João Pereira Caldas (1772-1780) ordenou o registro da cópia do regimento de Negreiros num livro da secretaria de governo do Estado do Grão-Pará e Rio Negro (APEP, códice 1, doc. 1) 12 .

Em relação aos efetivos ocupantes dos postos oficiais das ordenanças do Estado, encontramos somente a cópia de oito patentes registradas num livro da secretaria de governo referente ao governo, sucedido entre os anos de 1682 e 1685, de Francisco de Sá e Meneses (BA, cód. 51-IX-31) ${ }^{13}$. Todas as patentes são de capitão de companhia de infantaria: uma da capitania do Maranhão, cinco da capitania do Pará e duas da Vila da Vigia (BA, cód. 51-IX-31, f. 6, 19, 29, 44v., 45, 70, 79v., 94v.). Possuímos informações detalhadas sobre as carreiras de seis desses capitães. Sobre essas, com exceção de Luciano Gomes, que serviu pouco mais de oito anos e foi nomeado capitão de ordenança do Pará, em 1685, todos serviram mais do que o tempo exigido para a ascensão ao cargo - nove ou dez anos, conforme a legislação, promulgada em 1645, conhecida como regimento das fronteiras (MENDONÇA, 1972, p. 634). Se nas tropas pagas ou regulares - em relação à segunda metade do século XVII (1643-1685) - a maioria dos capitães de infantaria nomeados (17 dos 
22) eram recrutados dentre aqueles que não construíram carreiras (pelo menos nove ou dez anos de serviço) no Estado do Maranhão e Grão-Pará (ROCHA, 2013, anexo VI e VII), no caso dos capitães de ordenança a situação se inverte: todos, sem exceção, construíram carreiras sólidas na Amazônia. Dois deles, Antônio da Costa Silva e João Valente de Oliveira, atuaram em cargos camarários (o primeiro na câmara de São Luís e o segundo na de Belém), o que não ocorrera com nenhum dos capitães nomeados para a tropa paga (ROCHA, 2013, anexo VI e VII). Somente um indivíduo, João Lopes Guimarães, havia servido fora do Estado, mas, mesmo assim, por pouco tempo - servira quatro anos no Minho, embarcou para o Estado do Brasil com a missão de lutar na guerra contra os holandeses, foi enviado preso pelos flamengos para o Estado do Maranhão e Grão-Pará e serviu nessa região por mais de 14 anos até ser nomeado, em 1682, capitão de ordenança do Pará. Daqueles que possuíam carreiras estritamente militares, quatro dos seis, todos progrediram até o posto de alferes antes da nomeação à capitão (três atuaram como sargento, posição anterior a de alferes, e dois serviram como ajudante, posição posterior a de alferes). Essas patentes indicavam a forte autoridade do governador sobre a escolha dos capitães de ordenança, já que, sem exceção, eram providos pela referida autoridade - pois os textos dessas cartas patentes informavam que os oficiais respectivos foram eleitos e nomeados pelo governador - e um topos específico (servirá "enquanto eu houver por bem e não mandar o contrário") insinuava que só o mesmo governante poderia os destituir.

Assim como no caso das câmaras, os ofícios das ordenanças também foram alvos de disputa entre os "homens bons" e as autoridades régias (principalmente os governadores). A preocupação era a inflação do número de oficiais e, assim, de nobres. Uma denúncia da década de 1670 informava que os governadores do Estado do Maranhão e Grão-Pará costumavam conceder postos da tropa de ordenança aos camarários, seus filhos, genros ou outros parentes para garantir a governabilidade, isto é, quando visavam obter determinadas decisões ou certos favores das câmaras. Assim sendo, conforme tal denúncia, existia uma multiplicidade de cargos desse tipo de tropa, "que me parece são poucos os cipós que há no Estado para os proverem em insígnias se todos os andarão arvorados". A principal crítica recaía sobre a capacidade dos governadores de "criar" a "nobreza" ou "fidalguia", uma vez que, sem que houvesse merecimento dos nomeados mais que o "interesse" e a "conveniência" dessas autoridades, a "milícia foi o principal motivo da fidalguia daqueles 
moradores e perturbação daquele Estado: pois nele se não tem por honrado o que não ocupou, ou ocupa posto" (BA, 50-V-37, n. 138)

Em 1686, após as já mencionadas eleições e nomeações realizadas pelo governador Francisco de Sá e Meneses (1682-1685), o governador Gomes Freire de Andrade (1685-1687) enviou carta ao monarca descrevendo uma reclamação dos oficiais da Câmara de São Luís. Essa narrava as intervenções dos governadores nas eleições dos capitães e dos demais cargos da ordenança. Para garantir a faculdade de eleger esses postos, apresentavam argumentos diversos: citavam o regimento concedido a Vidal de Negreiros em 1655, que, ordenando a obediência ao regimento de D. Sebastião de 1570, garantia às câmaras a escolha dos oficiais das ordenanças; afirmavam que os governadores nomeavam muitos capitães para uma só companhia, o que ocorria "por meios ilícitos"; e informavam que tais intervenções rebaixavam as qualidades dos oficiais e aumentavam o número de privilegiados, cidadãos e/ou nobres - até mecânicos (não mais se considerando "plebeus") e índios queriam servir na câmara e, assim sendo, não mais trabalhavam para poder conquistar tal honra. Conforme a descrição do governador, as Câmaras de São Luís e Belém (que enviava carta anexa) solicitavam a manutenção da jurisdição da coordenação das eleições dos oficiais das ordenanças, pois, assim, elegeriam pessoas idôneas, "pela autoridade e experiência militar, e que haviam sido vereadores passando também para alferes os filhos dos cidadãos". O Conselho Ultramarino acabou acatando a posição comum de Gomes Freire (subtendida em sua descrição da carta da câmara) e do procurador da Coroa; e sugeria ainda que, após as escolhas dos oficiais das ordenanças por parte de ambas as câmaras, o governador possuiria autoridade para aprovar o eleito e esse deveria solicitar a confirmação régia do seu cargo $(\mathrm{AHU}, \text { cód. } 274, \text { f. } 54 \text { e 54v. })^{15}$. Essa proposta virou norma em carta régia do mesmo ano (1686) enviada ao sucessor de Freire de Andrade, o governador Arthur de Sá e Menezes (1687-1690) (AHU, cód. 268, f. 55) $)^{16}$.

Em carta régia de abril de 1688, talvez em função da conflituosa conjuntura que se apresentava (guerras contra os franceses no Cabo Norte e contra as tribos "bárbaras" no sertão), o monarca ordenava a Artur de Sá e Menezes a organização e um levantamento numérico, que deveria ser enviado ao centro monárquico, das ordenanças do sertão do Estado. Visava à facilidade de reunir e disciplinar esses homens dispersos pelas calhas dos rios, e, inclusive, permitia ao governador o provimento "dos mais postos que vos parecerem 
necessários [...] com declaração que havendo de criar algum posto de novo me deis primeiro conta". A mesma ordem foi remetida ao provedor mor da fazenda do Estado (AHU cód. 268, f. 60 $)^{17}$. Em resposta elaborada em outubro do mesmo ano (1688), Sá e Menezes considerava impossível arrumar as ordenanças em distritos (em função das distâncias das fazendas pelos rios e da necessidade dos recrutados de assistirem as suas lavouras) e julgava desnecessário criar postos, pois os exercícios militares eram realizados nas praças de Belém e São Luís e, para tal, "bastavam os oficiais de guerra que nela assistem". Por fim, indicava a expansão das ordenanças pelo sertão: nos rios Itapecuru e Mearim já existiam moradores comandados por seus respectivos capitães (AHU cód. 274, f. 66) ${ }^{18}$.

O regimento do secretário de governo do Estado, também elaborado em abril de 1688, reiterava a necessidade de elaborar listas das tropas (não se refere especificamente às tropas de ordenanças ou regulares), a serem enviadas ao Conselho Ultramarino, e de registrar as patentes dos oficiais das ordenanças (ajudantes, capitães e postos superiores). De uma taxa necessária à elaboração desses e de outros documentos (os chamados emolumentos), ordenava o regimento, os secretários obteriam os seus rendimentos, pois se travava de um ofício trienal não remunerado pela fazenda real. Dentre outros documentos, os emolumentos também deveriam ser retirados dos registros das patentes régias - patentes das tropas pagas ou confirmações régias dos postos das ordenanças (APEP cód. 1, doc. 2) ${ }^{19}$. Em carta ao rei de fevereiro de 1691, o secretário de governo (posto "novamente criado") Antônio Marcos da Fonseca se queixava dos baixos rendimentos auferidos. Afirmava que eram poucos os provimentos de postos e ofícios, pois, em relação às ordenanças, existiam somente três capitães (mesmo número da tropa paga) "e agora novamente se introduziu serem providos pelas câmaras, e as patentes feitas pelos escrivães delas, não obstante ser um dos capítulos do meu regimento" (AHU Pará, cx. 3, doc. 291) ${ }^{20}$. Uma carta régia enviada ao governador Antônio de Albuquerque Coelho de Carvalho (1690-1701) em setembro do mesmo ano (1691), reiterava a obediência, no que se refere às patentes de ordenança, ao regimento do secretário de governo do Estado. Citando diretamente a queixa do secretário acima referida, informava que os governadores se recusavam a aprovar as patentes elaboradas pelas câmaras, conforme exigia a carta régia de 1686, e "nem algumas pessoas mais beneméritas aceitar os ditos postos por semelhantes patentes" (AHU, cód. 268, f. 87) ${ }^{21}$. Por fim, o monarca relembrava a carta régia de 1686: 
[...] tenham entendido que aos oficiais da câmara não toca mais que proporem sujeitos para esses postos, e ser a aprovação vossa, mandandoIhes passar patentes deles sobrescritas pelo secretário declarando aos providos hão de mandar ao reino buscar a confirmação destas nomeações na forma que se pratica em todas as conquistas (AHU, cód. 268, f. 87).

Cabe informar que o conflito pelo controle do oficialato das Câmaras e das ordenanças do Estado, envolvendo a nobreza local e as autoridades régias (especialmente os governadores e os ouvidores), perdurará no século XVIII. Como foi observado em outros estudos, por um lado, as Câmaras continuarão a conceituar linhagens da nobreza local com base no controle das duas instituições em questão, no respeito aos privilégios adquiridos e na ideia de que a conquista, a restauração e/ou a colonização da região foi, em grande parte, realizado às custas dos sangues e das fazendas - sem a recorrência à fazenda real - desses cidadãos ou nobres. Por outro lado, sem nunca alijar de vez as câmaras (que continuariam a propor os oficiais), as leis régias progressivamente passaram a garantir aos governadores a jurisdição de prover os oficiais das ordenanças. Como mostram esses estudos, isso não ocorreu sem que houvesse conflitos entre as partes (nobreza local e autoridades régias) (ROCHA, 2012; e ROCHA, 2015).

\section{CONSIDERAÇÕES FinaIS}

Em síntese, a literatura portuguesa conceituava de forma diferenciada os diversos graus de nobreza então existentes e distiguia, claramente, por meio de mercês e/ou cargos específicos, as elites "local" (a nobreza da terra) e "extralocal" (a nobreza natural e a nobreza civil ou política, ou seja, nobrezas reconhecidas como tais, não apenas na região de sua residência, mas em todos os rincões do império). Embora em posições distintas, tendo em mente as elites locais da América Portuguesa, alguns princípios regulavam as nobrezas dos dois extremos da cadeia hierárquica (nobreza natural e nobreza local): a ideia de que os mais nobres eram os mais capazes servidores; a participação no governo, na administração e em guerras decisivas para o império (a Guerra da Restauração de Portugal, a conquista e a restauração da América Portuguesa); a hereditariedade do prestígio e do status; e, por fim, a clara identificação e delimitacão dos seus membros, isto é, o recrudescimento de linhangens específicas (visto que a inflação do número de nobres era uma preocupação latente). Em parte, no que se refere à elite local do Estado do Maranhão e Grão-Pará, o uso difuso ou a apropriação de termos específos (cidadão, nobreza e, mesmo, fidalguia), o embate entre a elite local e as autoridades régias pelo controle dos cargos (conflito equilibrado pela 
monarquia) e o respeito aos estigmas de qualidade (limpeza sangue e defeito mecânico) eram elementos utilizados para tentar consolidar o grupo.

FONTES MANUSCRITAS

\section{1655, Abril, 9, Lisboa}

CONSULTA do Conselho Ultramarino ao rei D. João IV, sobre a petição dos procuradores do Estado do Maranhão, para que lhes passe a provisão de privilégios em termos semelhantes àqueles já concedidos aos cidadãos do Porto.

AHU_ACL_CU_009, Cx. 3, D. 361

2 Provisão régia que concede o privilégio dos cidadãos da cidade do Porto aos cidadãos de $\mathrm{S}$. Luís do Maranhão. Lisboa, 15 de abril de1655. Arquivos Nacionais da Torre do Tombo, Chancelaria de D. João IV, livro 27, fólio 118 verso.

\section{1655, Junho,2, Lisboa}

CONSULTA do Conselho Ultramarino para o rei D. João IV, sobre pedido dos moradores da cidade de Belém do Pará, para que lhes sejam concedidos os mesmos privilégios dados aos moradores do Maranhão e da cidade do Porto, justificando-se pelos serviços que prestaram com a reconstrução da cidade e da expulsão dos holandeses.

AHU_ACL_CU_013, Cx. 2, D. 95.

\section{4 [post. 1655, Junho, 20], Lisboa}

REQUERIMENTOS do procurador do Estado do Maranhão, Paulo da Silva Nunes, para o rei D. João IV, sobre a descrição do dito Estado e de suas necessidades, nomeadamente em termos de defesa e de provimento, com referência à concessão dos privilégios dos cidadãos do Porto e do Maranhão. Anexo: cópias da carta dos privilégios dos cidadãos da cidade do Porto e de Lisboa e da provisão sobre os privilégios concedidos aos cidadãos do Maranhão.

\section{AHU_ACL_CU_009, Cx. 3, D. 367}

\section{1662, Julho, 30, São Luís do Maranhão}

CARTA dos oficiais da câmara da cidade de São Luís do Maranhão para o Conselho Ultramarino, em que solicitam que lhes sejam preservados privilégios, e que os governadores não se intrometam na jurisdição da dita câmara, nem anexem os seus oficiais.

AHU_ACL_CU_009, Cx. 4, D. 453

6 Carta Régia de D. Pedro II ao governador do Estado do Maranhão, Antônio de Albuquerque Coelho de Carvalho, solicitando informações do mesmo governador sobre as queixas da Câmara de Belém. Lisboa, 11 de dezembro de 1698. Arquivo Histórico Ultramarino, códice 268, fólio 137.

7 Carta Régia de D. Pedro II ao governador do Estado do Maranhão, Antônio de Albuquerque Coelho de Carvalho, ordenando que a Câmara de Belém seja ocupada por descendentes de nobres e cidadãos. Lisboa, 10 de Dezembro de 1698. Arquivo Histórico Ultramarino, códice 268, fólio 138 verso. 
Arquivo Público do Estado do Maranhão, Livro da Companhia da nobreza. São Luís, 16891710.

\section{1728, Setembro,14, Belém do Grão-Pará}

CARTA do governador e capitão-general do Estado do Maranhão, Alexandre de Sousa Freire, para o rei $D$. João $V$, em resposta à provisão régia de 13 de Outubro de 1727 , sobre a falta de soldados para servir na capitania e informando acerca da guerra que se verifica no Rio Negro contra o gentio bárbaro Mayapema. Anexo: listas e mapa.

AHU_ACL_CU_013,Cx.11, D. 974.

10 [post.1730, Setembro,20, Pará]

MAPA da Infantaria Paga que se encontra na praça da capitania do Pará elaborado de acordo com a mostra geral de 20 de Setembro de 1730.

Anexo: listas.

AHU_ACL_CU_013, Cx. 12, D. 1141.

\section{1 [post.1730, Setembro,20, Pará]}

MAPA das Ordenanças que se encontram na praça da capitania do Pará elaborado de acordo com a mostra geral de 20 de Setembro de 1730.

Anexo: listas.

AHU_ACL_CU_013, Cx. 12, D. 1142.

12 Regimento, do rei D. João IV, remetido ao governador do Estado do Maranhão, André Vidal de Negreiros. Lisboa, 14 de Abril de 1655. Arquivo Público do Estado do Maranhão, códice 1, documento 1.

13 Livro da secretaria de governo do Estado do Maranhão e Grão-Pará referente ao governo de Francisco de Sá e Meneses. São Luís, 1682-1685. Biblioteca da Ajuda, códice 51-IX-31.

14 Representação ao príncipe regente D. Pedro II de Simão da Costa e Sousa sobre as desordens relativas aos oficiais do Estado do Maranhão e Grão-Pará.Lisboa,21 de outubro de 1679. Biblioteca da Ajuda, códice 50-V-37, documento número 138.

15 Consulta do Conselho Ultramarino sobre as queixas da câmara de São Luís sobre acerca das nomeações dos oficiais das ordenanças por parte dos governadores. Lisboa, 2 de Dezembro de 1686.

16 Carta Régia de D. Pedro II ao govenador Arthur de Sá e Meneses sobre a escolha dos oficiais das ordenanças do Estado do Maranhão e Grão-Pará. Lisboa 20 de dezembro de 1686. Arquivo Histórico Ultramarino, códice 268, fólio 55.

17 Carta Régia de D. Pedro II ao provedor da fazenda do Estado do Maranhão e Grão-Pará acerca da organização das ordenanças do Estado do Maranhão e Grão-Pará. Lisboa 6 de Abril de 1688. Arquivo Histórico Ultramarino, códice 268, fólio 60. 
18 Consulta do Conselho Ultramarino sobre a organização das ordenanças do Estado do Maranhão e Grão-Pará. Lisboa, 6 de outubro de 1688. Arquivo Histórico Ultramarino, códice 274, fólio 66.

19 Regimento do secretário de governo do Estado do Maranhão e Grão-Pará. Lisboa, 9 de Abril de 1688. Arquivo Público do Estado do Pará, códice 1, documento 2.

\section{1691, Fevereiro,26, Belém do Grão-Pará}

CARTA do secretário do Governo do Estado do Maranhão, António Marcos da Fonseca, para o rei [D. Pedro II], sobre o rendimento do cargo que desempenha e as vantagens para a sua existência na capitania do Pará, e acerca do provimento de pessoas para as Companhias de Ordenanças.

AHU_ACL_CU_013, Cx. 3, D. 291.

21 Carta Régia de D. Pedro II ao govenador Arthur de Sá e Meneses que reiterava uma Carta Régia de 1686 sobre o provimento dos oficiais de ordenança. Lisboa, 19 de fevereiro de 1691. Arquivo Histórico Ultramarino, códice 268, fólio 87.

\section{REFERÊNCIAS}

BICALHO, Maria Fernanda. As câmaras ultramarinas e o governo do império. In: FRAGOSO, João; BICALHO, Maria Fernanda; e GOUVÊA, Maria de Fátima (Org.). O Antigo Regime nos trópicos. A dinâmica imperial portuguesa (séculos XVI-XVIII). Rio de Janeiro: Civilização Brasileira, 2001.

BICALHO, Maria Fernanda. A cidade e o império. O Rio de Janeiro no século XVIII. São Paulo: Companhia das Letras, 2003.

BOXER, Charles R. O império Marítimo Português. São Paulo: Companhia das Letras, 1994.

CORRÊA. Helidacy Maria. "Para aumento da conquista e bom governo dos moradores": a câmara de São Luís e a política da monarquia pluricontinental no Maranhão. In: FRAGOSO, João; SAMPAIO, Antônio Carlos. Monarquia Pluricontinental e a governança da terra no ultramar atlântico luso. Rio de Janeiro: Mauad X, 2012.

FLORY, Rae; SMITH, David Grant. Bahian Mechants in the Seventeenth and Eighteenth Centuries. The Hispanic American Historical Review, v. 58, n. 4, 1978.

FRAGOSO, João. A formação da economia colonial no Rio de Janeiro e de sua primeira elite senhorial (séculos XVI e XVII). In: FRAGOSO, João; BICALHO, Maria Fernanda; GOUVÊA, Maria de Fátima (Org). $O$ Antigo Regime nos trópicos. A dinâmica imperial portuguesa (séculos XVI-XVIII). Rio de Janeiro: Civilização Brasileira, 2001.

FRAGOSO, João. Fidalgos e parentes de pretos: notas sobre a nobreza principal da terra do Rio de Janeiro (1600-1750). In: FRAGOSO, João; ALMEIDA, Carla Maria de; SAMPAIO, Antônio Carlos. Conquistadores e negociantes. História de elites no Antigo Regime nos trópicos. América lusa, séculos XVI a XVIII. Rio de Janeiro: Civilização Brasileira, 2005.

MENDONÇA, Marcos Carneiro de (Org.). Raízes da formação administrativa do Brasil. Rio de Janeiro: Conselho Federal de Cultura, 1972. 
MELLO, Evaldo Cabral de. A fronda dos mazombos. Nobres contra mascates, Pernambuco, 1666-1715. São Paulo: Editora 34, 2003.

MELLO, Evaldo Cabral de. Rubro Veio. O imaginário da restauração pernambucana. 3. ed. São Paulo: Alameda, 2008.

MONTEIRO, Nuno G. (Coord.). História dos municípios e do poder local. Lisboa: Editorial Estampa, 1996.

MONTEIRO, Nuno G. Poder senhorial, estatuto nobiliárquico e aristocracia. In: HESPANHA, Antônio Manuel (Coord). História de Portugal. v. 4. Lisboa: Editorial Estampa, 1998a.

MONTEIRO, Nuno G. Concelhos e as comunidades. In: Antônio Manuel Hespanha. (coord.) História de Portugal. Vol. 4. Lisboa: Editorial Estampa, 1998b.

MONTEIRO, Nuno. O crepúsculo dos grandes. Lisboa: Imprensa Nacional-Casa da Moeda, 2003a.

MONTEIRO, Nuno G. Elites locais e mobilidade social em Portugal nos finais do Antigo Regime. In: MONTEIRO, Nuno G. Elites e Poder. Entre o Antigo Regime e o Liberalismo. Lisboa: Imprensa de Ciências Sociais, 2003b.

MONTEIRO, Nuno. O Ethos nobiliárquico no final do Antigo Regime: poder simbólico, império e imaginário social. Almanak braziliense. Lisboa, n², 2005.

OLIVEIRA, Luiz da Silva de Oliveira. Privilégios da nobreza e fidalguia de Portugal. Lisboa: ANHP, 2002.

ROCHA, Rafael. A construção da nobreza no Pará setecentista. In: Caminhos da Intolerância. Rio de Janeiro: Contracapa, 2012.

ROCHA, Rafael Ale. A elite militar no Estado do Maranhão. Tese de doutorado. Niterói: UFF, 2013.

ROCHA, Rafael Ale. O provimento dos oficiais da tropa de ordenança: poder, instituições e elites locais no Estado do Maranhão e Grão-Pará (primeira metade do século XVIII). In: CARDOSO, Alírio; BASTOS, Carlos A.; e NOGUEIRA, Maria S. História Militar da Amazônia. Guerra e Sociedade (séculos XVII-XIX). Curitiba: CRV, 2015.

SCHWARTZ, Stuart B. Segredos internos. Engenhos e escravos na sociedade colonial - 1550-1835. São Paulo: Companhia das Letras, 2005.

XAVIER, Ângela e HESPANHA, Antônio. A representação da sociedade e do poder. In: HESPANHA, Antônio (cord.). História de Portugal. v. 4. Lisboa: Editorial Estampa, 1998.

HESPANHA, Antônio. As vésperas do Leviathan. Lisboa: Almedina, 1994. 